spells of fever came under the author's care. The assortment of regularly repetitive disorders in otherwise healthy persons suggested the existence of some rhythmic disturbance common to each patient. In the case of one of the three, his enquiring mind and lively scientific interest stretched even further, and she became his wife. This monograph is consequently dedicated to his wife who endures one of these maladies unallayed by physicians. The reader will find examples of the periodicity not only of fever but also of peritonitis, cedema, purpura, mucocutaneous syndromes, arthralgia, sialadenosis, pancreatosis, psychoses, paralyses, hypertension and also periodic involvement of renal and respiratory tract involvement. It is nice to feel that the literature relating to all these disparate syndromes has been brought together as a ready reference for the interested clinician. Even more important in bringing them together is the way in which it strengthens Dr. Reimann's arguments for the periodic diseases and reaffirms Osler's observation that there is a positive advantage in recognising the affinities and the strong points of similarity in affections usually grouped as separate diseases.

Valuable as it is, it is difficult to understand why this small paperback should cost $44 \mathrm{~s}$. when a recent and much larger paperback covering recent advances throughout medicine should only cost 30 s.

\section{Emotions and Emotional Disorders}

A Neurophysiological Study. ERNEST GellHORN, M.D. and G. N. LOOFBOURROW, Ph.D. Pp. xii +496 illustrated. New York \& London : Harper and Low. 1963. 90s.

Professor Gellhorn has concentrated his research for many years on the study of autonomic and especially hypothalamic activity. In this book he finally attempts to interpret a great deal of normal psychology and mental illness in terms of these phenomena. This is admirable and any criticisms must be put in the context of these having been freely invited by the author's enthusiastic approach. Indeed, he seems to be himself constantly attempting to evoke comment and discussion as he develops his theme. The early chapters are devoted to a discussion of basic neuro-physiology which are clear and useful; then there are sections on the socalled hypothalamic tests and on various aspects of psycho-physiology. The second half of the book is mainly devoted to discussing functions of the autonomic nervous system in relation to psychosomatic illness, neuroses and psychoses and their treatments. At the end of each chapter there is a summary which is usually comprehensive and lucid, even where the main text has been more difficult to understand.

He presents a considerable amount of detail of experimental work in his own and closely allied fields and in this connection there is a memorable list of nearly 1,000 references at the end of the book. It is a pity that these do not have page references back to the text. In his own field the mecholyl and noradrenaline tests, which he regards as measures of sympathetic and parasympathetic reactivity and which form an important cornerstone for his subsequent hypotheses have been the subject of well-documented controversy. His concept of 'tuning' of automatic centres is not clear; at one time he defines it as a quantitative phenomenon whilst on another occasion he refers to apparently qualitatively different processes of 'sensitisation' and 'facilitation' as being part of it. ¿

However, it is his attempt to integrate a varietyc. of animal and human experimental and clinical data, philosophy and monisitic theory that his arguments become most difficult to follow. To facilitate the extension of his own concepts to embrace and explain so much of human behaviour, he draws heavily on such work as the poorly controlled bio- $\frac{\bar{s}}{5}$ chemical studies of Hoskins on chronic schizo- $\mathbb{D}$ phrenia, the controversial work by Shagass on sedation threshold which is still developmental, $\infty$ Hess' hypotheses of ergotrophic and trophotrophic psycho-physiological processes in animals, and he samples the sometimes conflicting studies mainly on $\overrightarrow{\vec{\omega}}$ animals in the field of psycho-pharmacology. In a continued attempt to be all-embracing within his own uni-dimensional view, he makes statementso like "emotions and instinctual drives occur only in 3 . the alented organism". Surely, the problems of $A$ dreaming apart, it is common clinical experiencethat patients can sometimes be helped to abreact $₫$ primitive feelings by reducing their level of con- $-\overrightarrow{.}$ sciousness. Again, according to him, tranquillisers of always depress mood; peptic ulcer and hyperten- $\circ$ sion could presumably never be found to co-exist $\supset$ on the basis of his hypothesis that one reflects vagotonic and the other sympathotonic dominance, $c$ and so on. The book closes with suggestions for further research which the author would obviously dearly like to pursue himself.

\section{Tuberculosis in Twins}

Barbara Simonds, for the Prophit Committee of the Royal College of Physicians. Pp. 81, London: Pitman Medical. 1963. 10s. 6d.

The theory of heredity in tuberculosis was $\stackrel{\odot}{\varrho}$ accepted universally until Villemin demonstrated in $\overrightarrow{\bar{O}}$ 1865 that the disease-was transmissible by inocula- 3 tion. Since then, belief in the existence of $a \frac{3}{J}$ hereditary tuberculous diathesis has received considerable support, despite the difficulties that exist in determining the relative importance of hereditary and environmental factors in the development of a 3 disease that is both infective and prevalent.

The purpose of the twin studies, so admirably 3 described in this booklet, was to obtain evidence on the role of hereditary susceptibility in the development of tuberculosis. Meticulous care was taken over the essential requisites of twin studies, $ᄋ$ namely, the collection of a large unbiassed series of twins with one or both of the twins tuberculous $\frac{D}{2}$ and the diagnosis of zygocity of the twin pairs.

The survey demonstrated a higher concordance $\overline{\mathrm{N}}$ rate for tuberculosis in monozygotic twins than in $\sigma$ dizygotic twins. The difference was, however, much $\mathrm{N}$ less than described by most other authors and $N$ could be explained by the greater physical contact $\mathrm{N}$ of monozygotic twins, by greater incidence of mono- $\sigma$ zygotic index cases with a positive sputum and $a_{0}$ greater number of susceptible females among the monozygotic twins.

The study is presented in an interesting and lucid $\stackrel{\infty}{+}$ manner, the discussion is balanced and the con- $T$ clusions convincing. It is a delightful little book $\bar{O}$ which students of tuberculosis and of heredity would enjoy reading. 